\title{
THE ROLES OF WITHDRAWAL IN THE NEGOTIATOR PERSONALITY-TACTIC RELATIONSHIP
}

\author{
Pui Ting CHOW ${ }^{1}$, Sai On CHEUNG ${ }^{2}$, Chiu Yan YOUNG ${ }^{3}$, Chi Kit WAH ${ }^{4}$ \\ Department of Architecture and Civil Engineering, College of Science and Engineering, City \\ University of Hong Kong, 83 Tat Chee Av., Kowloon Tong, Hong Kong \\ E-mails: ${ }^{1}$ ronnie.chow.pt@hotmail.com (corresponding author); ${ }^{2}$ saion.cheung@cityu.edu.hk;
}

Received 24 February 2012; accepted 19 December 2012

\begin{abstract}
The personality of a negotiator shall affect his choice of tactics. Moreover, mixed predictions of the personality-tactic relationship have been derived from prior studies. One possible explanation is the influence of other intervening factors. In this regard, this study examines the role of withdrawal, as an intervening variable, in the negotiator personality-tactic relationship. State of withdrawal refers to the level of interest to continue with a negotiation. In a state of complete withdrawal, the interest to continue no longer exists and breakdown of the negotiation is inevitable. With the participation of practicing professionals, an experiment was used to collect data for the study. It was found that competitors are prone to withdraw and use more distributive tactics. However, this pattern changes with the composition of the dyad. If the negotiating counterpart is a cooperator, a competitor will adopt a more integrative approach. This finding reminds the importance of the personality factor in selecting members of a negotiating team.
\end{abstract}

Keywords: personality, organization, strategy, strategic management, tactic, withdrawal, negotiator behavior, negotiation outcome.

JEL Classification: L20.

\section{Introduction}

Construction contracting environment is inherently dispute-laden and most of the construction disputes are settled through negotiation (Cheung, Yiu 2006). However, it is thought provoking that some negotiations fail even when mutually acceptable settlement options are notable (O'Connor, Gladstone 2015; Olekalns, Smith 2013). This phenomenon does not fit well with the rational school that assumes negotiators are maximisers. Behaviorists have attributed this happening to the influence of negotiators' personal qualities - personality (O'Connor, Gladstone 2015). Cheung et al. (2009) further found that a negotiator's personality is intrinsically linked to his choice of tactic because personality influences the way a negotiator interprets a dispute. For example, a cooperative negotiator may view a challenge by his counterpart as an attempt to explore better options, but a competitive negotiator may view the same challenge as a threat. This type of attitudinal responses would influence a negotiator's interest to continue with the 
negotiation and thereby the tactics that he will use. Apart from personality, negotiators also employ tactics responsive to the contextual constraints. Mixed predictions on the causal relationship between personality and tactic have been reported (Yiu et al. 2008). For example, Toma et al. (2012) suggested that cooperators tend to employ integrative tactics and competitors use distributive tactics more readily. However, O'Connor, Gladstone (2015) proposed that competitors use more integrative tactics to achieve their self-interest goal and cooperators use more distributive tactics to protect themselves from being exploited. It is, therefore, plausible that there may be some intervening variables between personality and tactic. Volkema et al. (2010) suggested that negotiators who have low level of interest to negotiate would reject mutually beneficial offers when his counterpart is using distributive tactics. Withdrawal, defined as the loss of interest to continue with a negotiation, is suggested to be an intervening variable. Withdrawal is also disruptive for its detrimental effect on prospective negotiated settlement (Pruitt, Kim 2004; Rodriguez Mosquera et al. 2008). The study aims to offer an explanation to the intriguing observation that some negotiations fails to capitalize on the available mutually beneficial settlement options by examining the relationship among personality, tactic and withdrawal. In particular, the influence of withdrawal on the choice of tactics with respect to the personality of the negotiator is examined. The findings and discussions of withdrawal would help to explain the mixed predictions on the personalitytactic relationship. This paper begins with a review of the literature on personality, tactic and withdrawal. Hypotheses are then developed and followed by discussion on research methodology. Data analysis and findings are then presented. The paper ends with the discussion on theoretical contributions, managerial implications, and limitations.

\section{Literature review}

\subsection{Personality}

Negotiation studies identify negotiators who consider only own concern as competitors, whereas ones who consider both own and the counterparts' concern as cooperators (Prietula, Weingart 2011). Competitors and cooperators use tactics that reflect their preference in the types of gains and outcomes. In term of tactics, competitors would adopt high-handed approaches and treat negotiation as distributive (Volkema et al. 2010), while cooperators would more readily employ integrative strategies that explore joint gain potential and expand common interests (Lewicki et al. 2010; Pruitt, Kim 2004). In term of outcomes, competitors focus mainly on maximizing own outcomes, while cooperators expect compliment.

\subsection{Negotiator tactics}

Negotiation research identifies two principle types of tactic: distributive and integrative (Olekalns, Smith 2013; Prietula, Weingart 2011). Distributive tactics aim to divide resources among negotiating parties and integrative tactics seek to maximize the overall outcome (Pruitt, Kim 2004). The former prompts positional bargaining and bluffing, while the latter encourages information exchanges and facilitates mutually beneficial 
trade-offs (Olekalns, Smith 2003; Thompson 2012). Using appropriate tactics is part of the game plan of any negotiation. In general, distributive tactics are used to assert positions and press for concessions through forceful argument and sometimes threats (Rodriguez Mosquera et al. 2008). On the other hand, integrative tactics are used to strive for creation of joint values and direct at improving the understanding of the needs and wishes of the negotiating parties. Enhancing information exchange to derive mutually beneficial agreement is commonly observed in integrative negotiations (Prietula, Weingart 2011).

\subsection{Withdrawal}

A negotiator who has a strong desire to settle will take a positive approach in a negotiation and enthusiastically consider every proposal on the table. Pragmatically, a negotiation with a withdrawing party is doomed. Withdrawal happens when a negotiator loses interest to continue with the negotiation (Cheung, Chow 2011; Olekalns, Smith 2003). The states of withdrawal range from "continuation" to "breakdown". The lower the interest to continue, the higher the state of withdrawal and the more likely the negotiation will breakdown (O'Connor, Gladstone 2015). Furthermore, it is extremely resource-laden to resume a withdrawn negotiation as noted in the deadlock of many international disputes (Cheung, Chow 2011). In these cases, withdrawal had led negotiations to stalemates or impasses even though prospective settlement options were notably present (Kesting, Smolinski 2007; O’Connor, Gladstone 2015; Prietula, Weingart 2011). If withdrawing behaviors occur at the early stage of a negotiation and are not unrestrained, the chance of a negotiation breakdown intensifies (Cheung, Chow 2011). In other words, high withdrawal is accompanied by the use of distributive tactics and low withdrawal leads to more use of integrative tactics (O'Connor, Gladstone 2015; Rodriguez Mosquera et al. 2008; Sinaceur, Tiedens 2006; Thompson 2012).

\section{Theoretical framework and hypotheses}

This study posits that choice of tactic is contingent to the contexts of a negotiation. It is hypothesized that personality and withdrawal influence the choice of tactic and thus ultimately affect the negotiation outcome (Cheung, Chow 2011; Yiu et al. 2008). In a negotiation, the parties engage in a joint decision process of getting a mutually acceptable settlement. Consensual agreement is a must as none of the parties has any authority to adjudicate. A negotiation begins with either distributive or integrative responses and largely depends on the negotiators' personality and his desire to negotiate - state of withdrawal (Bhanugopan, Fish 2006). In addition, research on personality and tactic in experimental gaming indicates that cooperators would become less cooperative if their counterparts consistently employ distributive tactics (Olekalns, Smith 2003; Prietula, Weingart 2011). Negotiators may also withdraw in response to the distributive behavior used by individualistic opponents (Rhoades et al. 2001). The tendency to withdraw, at the same time, negatively influences the way negotiators interpret their counterparts' tactics, especially in face-to-face negotiations (O'Connor, Gladstone 2015; Olekalns, Smith 2003). It is proposed that competitive mindset; high withdrawal and distributive acts have negative influence on a negotiation. Five hypotheses have been developed: 
H1: Competitors have higher state of withdrawal than cooperators.

H2: The higher the state of withdrawal of a negotiator is, the more likely the negotiation is to be conducted in a distributive fashion.

H3: The higher the state of withdrawal of a negotiator is, the lower is the utility of the achieved outcome.

H4: Competitors use more distributive tactics than cooperators.

H5: Distributive negotiations result in lower joint gain than integrative negotiations.

\section{Methodology}

\subsection{Experiment design}

An experiment was used to collect data to test the hypotheses (Olekalns, Smith 2013; Pruitt, Kim 2004; Thompson 2012). The tasks to be negotiated were developed based on real-life disputes between main contractors and developers. The participants in each round of the bilateral negotiation were the sole representatives of the two organizations (the "Contractor" and the "Developer"). A pilot run with experienced construction professionals confirmed the relevance and appropriateness of the tasks. The pilot also indicates that the negotiation tasks could be completed from 30 minutes to an hour (Cheung, Chow 2011). The data collected from the subjects allow the researchers to make dyads comparisons (Olekalns, Smith 2013).

\subsection{Measurement scale}

\subsubsection{Personality}

A simplified decomposed-game was used to develop a dichotomy between competitors and cooperators (Olekalns, Smith 2013). The subjects had to choose between two options allocating the percentage of money to themselves and their counterparts; option 1 is $40 \%$ to themselves and $10 \%$ to their counterparts and option 2 is $30 \%$ to themselves and $30 \%$ to their counterparts (Prietula, Weingart 2011). The total of the outcome is not $100 \%$ to take account of the inherent transaction cost. The measurement of personality was taken at the registration of the experiment. An instruction from the company's senior management was used to induce external influence before the negotiation. The instruction of either "maximize own outcome" or "maximize joint outcome" was assigned to the subjects.

\subsubsection{Tactics}

A tactic may fall within a continuum between purely distributive and purely integrative. Distributive tactics focus on collecting more and giving less information; and pressing for concession, while integrative tactics stress the importance of exchanging priorities; showing insight into others' perspective; and developing trust, confidence and sympathy toward the other parties (Brett et al. 2007; Lewicki et al. 2010). A coding scheme developed from those used by Pruitt and Kim (2004) was employed in this study (Table 1). The negotiations were recorded then transcribed, translated and coded for analysis. The transcripts were coded by two raters. Any discrepancies between the 
Table 1. The coding of distributive and integrative tactics

\begin{tabular}{|c|c|c|}
\hline Coding & Tactic & Example \\
\hline DT_1 & Attacking the counterpart's position & Why you choose to ... in this issue? \\
\hline DT_2 & $\begin{array}{l}\text { Requesting bottom line of the } \\
\text { counterpart }\end{array}$ & What's your lowest possible price? \\
\hline DT_3 & Rejecting the counterpart's offer & I can't accept this. \\
\hline DT_4 & Referring to bottom line & I won't have other choices. \\
\hline DT_5 & $\begin{array}{l}\text { Notifying serious differences between } \\
\text { parties }\end{array}$ & I can't see that we have the same target. \\
\hline DT_6 & Expressing negative emotion word & It is ridiculous! \\
\hline $\mathrm{DT}_{-} 7$ & Using threat & $\begin{array}{l}\text { If you don't accept it, I will take legal } \\
\text { action. }\end{array}$ \\
\hline DT_8 & Abusing power & I am the one to determine the claim. \\
\hline DT_9 & Insisting in own position & As mentioned before, I want to ... \\
\hline $\mathrm{DT}_{-} 10$ & $\begin{array}{l}\text { Making offer which needs the concession } \\
\text { of other parties }\end{array}$ & I suggest you giving up.... this issue. \\
\hline IN_1 & Providing own priorities & $\ldots$ is the most important for me. \\
\hline IN_2 & $\begin{array}{l}\text { Making provision for preferences and/or } \\
\text { priorities }\end{array}$ & I would prefer ... when talking about... \\
\hline IN_3 & $\begin{array}{l}\text { Giving insight about other parties' } \\
\text { concern and/or situation }\end{array}$ & I know that your uncertainty is.... \\
\hline IN_4 & Notifying similarities between parties & I can see that we have the same target. \\
\hline IN_5 & $\begin{array}{l}\text { Notifying general differences between } \\
\text { parties }\end{array}$ & $\begin{array}{l}\text { I can see that we have the differences in } \\
\ldots .\end{array}$ \\
\hline IN_6 & Giving positive emotion word & That's great. \\
\hline IN_7 & Suggesting compromise & $\begin{array}{l}\text { I think we need to make concession on } \\
\text { this issue. }\end{array}$ \\
\hline IN_8 & $\begin{array}{l}\text { Guaranteeing the validation of previous } \\
\text { statement }\end{array}$ & $\begin{array}{l}\text { I must pay you the amount that we have } \\
\text { agreed. }\end{array}$ \\
\hline IN_9 & Exerting time pressure & I don't think we have much time. \\
\hline IN_10 & $\begin{array}{l}\text { Making explicit multi-issue trade-off } \\
\text { offer for resolution }\end{array}$ & $\begin{array}{l}\text { What about if we choose } \mathrm{A} \text { in } \ldots \text { and } \mathrm{B} \\
\text { in...? }\end{array}$ \\
\hline MI & Other & Maybe we should go on to other issues. \\
\hline
\end{tabular}

Notes: DT: Distributive Tactic; IN: Integrative Tactic; MI: Miscellaneous.

raters were resolved through discussion. The level of argument of the coded transcripts was checked by Kappa. Карpa, an inter-rater reliability test, is calculated by Eq. (1). Kappa of value from 0.70 to 0.74 are classified as very good, and those at or above 0.75 are classified as excellent (Bakeman, Robinson 2005). It is assumed that each unit to be coded has the same probability of accurate classification, and then the probability of 
chance agreement $\left(P_{c}\right)$ is $1 / k$, where $k$ is the number of categories in the coding scheme (Folger et al. 1984).

$$
\text { Kappa }=\frac{\left(P_{0}+P_{x}\right)}{\left(1-P_{c}\right)},
$$

where $P_{o}$ is the observed percentage agreement among coders and $P_{c}$ is the proportion of chance agreement.

\subsubsection{Withdrawal}

Manifestations of withdrawal include plans to search for alternative and general thoughts or considerations of quitting (Bhanugopan, Fish 2006). Increase in level of withdrawal weakens the ties of social relations between negotiators. Withdrawal has been linked with exhaustion, wearing out, failing, and ultimately burnout. Burnout takes the form of physical, emotional, and psychological response to stress (Bhanugopan, Fish 2006). Thus, burnout underpins decisions to withdraw which can be detected in negotiation by three measureable components (Cropanzano et al. 2003). The first component is a chronic state of exhaustion - emotional exhaustion. The second component is a type of interpersonal distancing and a lack of connectedness with the counterparts - depersonalization. The last component is a negative evaluation of the self - reduced personal accomplishment (Cheung, Chow 2011). Six indicators are used to measure the state of withdrawal in this study (Cheung, Chow 2011). In the experiment, two measurements of the state of withdrawal were made, one each at pre and post negotiation.

\section{Subjects and procedure}

In many negotiation studies, the subjects were university students (Rodriguez Mosquera et al. 2008; Prietula, Weingart 2011). In this study, practicing construction professionals participated as subjects to augment the authenticity of the findings. Prospective subjects were those who have experience in dispute negotiation and are currently practicing in the construction industry. Around 1000 construction practitioners were invited to participate in the study with their contacts obtained from company directories and the member lists of professional institutes such as the Hong Kong Institute of Surveyors (HKIS) and the Hong Kong Institution of Engineers (HKIE). Subjects were contacted either by phone or email. Participants were given confidential information on roles of and a 20-minute PowerPoint presentation of (1) the Project situation, (2) the four dispute issues to be negotiated, (3) the options available for each issue, and (4) instructions from the company's senior management before negotiation. The susceptibility of the subjects to their organization's instructions was checked by asking participant to identify their primary objective from three options, i.e. (1) maximize own gain, (2) maximize joint gain, or (3) none of these two.

\section{Tasks to be negotiated}

The scenario was about the construction of a commercial building with the use of Standard Form of Building Contract (the "Contract"). There are four issues in dispute: (1) rapid inflation of steel price, (2) additional sky garden, (3) prolonged inclement 
weather, and (4) change of supplier. Negotiators were allowed to continue the negotiation until they considered that no further progress could be made. Table 2 shows the payoff schedules for the Contractor and the Developer. The payoffs of Issues 1 and 3 are integrative in which better joint gain can be achieved if negotiators could make all concession trade-off. The payoffs of Issues 2 and 4 are distributive as the negotia-

Table 2. Payoff matrices of the negotiation

\begin{tabular}{|c|c|c|c|c|c|c|}
\hline \multirow{2}{*}{ Issue } & \multirow{2}{*}{ Option } & \multirow{2}{*}{\multicolumn{2}{|c|}{ Claim amount ${ }^{\mathrm{i}}(\mathrm{HK} \$)$}} & \multicolumn{3}{|c|}{ Monetary payoff $(\mathrm{HK} \$)$} \\
\hline & & & & Contractor & Developer & Sub-total \\
\hline \multirow{6}{*}{1} & A & 0 & $0 \%$ & 0 & 600,000 & 600,000 \\
\hline & $\mathrm{B}$ & $1,250,000$ & $25 \%$ & 344,415 & 554,328 & 898,743 \\
\hline & $\mathrm{C}$ & $2,500,000$ & $50 \%$ & 636,396 & 424,264 & $1,060,660$ \\
\hline & $\mathrm{D}$ & $3,750,000$ & $75 \%$ & 831,492 & 229,610 & $1,061,102$ \\
\hline & $\mathrm{E}$ & $5,000,000$ & $100 \%$ & 900,000 & 0 & 900,000 \\
\hline & $F^{\mathrm{ii}}$ & & & $-831,492$ & 229,610 & $-601,882$ \\
\hline \multirow{6}{*}{2} & A & 0 & $0 \%$ & 0 & 400,000 & 400,000 \\
\hline & $\mathrm{B}$ & $1,000,000$ & $25 \%$ & 75,000 & 300,000 & 375,000 \\
\hline & $\mathrm{C}$ & $2,000,000$ & $50 \%$ & 150,000 & 200,000 & 350,000 \\
\hline & $\mathrm{D}$ & $3,000,000$ & $75 \%$ & 225,000 & 100,000 & 325,000 \\
\hline & $\mathrm{E}$ & $4,000,000$ & $100 \%$ & 300,000 & 0 & 300,000 \\
\hline & $\mathrm{F}$ & & & 75,000 & 0 & 75,000 \\
\hline \multirow{6}{*}{3} & $\mathrm{~A}$ & 0 & $0 \%$ & 0 & 900,000 & 900,000 \\
\hline & $\mathrm{B}$ & 500,000 & $25 \%$ & 229,610 & 831,492 & $1,061,102$ \\
\hline & $\mathrm{C}$ & $1,000,000$ & $50 \%$ & 424,264 & 636,396 & $1,060,660$ \\
\hline & $\mathrm{D}$ & $1,500,000$ & $75 \%$ & 554,328 & 344,415 & 898,743 \\
\hline & $\mathrm{E}$ & $2,000,000$ & $100 \%$ & 600,000 & 0 & 600,000 \\
\hline & $\mathrm{F}$ & & & 229,610 & $-831,492$ & $-601,882$ \\
\hline \multirow{6}{*}{4} & $\mathrm{~A}$ & 0 & $0 \%$ & 0 & 300,000 & 300,000 \\
\hline & B & 750,000 & $25 \%$ & 100,000 & 225,000 & 325,000 \\
\hline & $\mathrm{C}$ & $1,500,000$ & $50 \%$ & 200,000 & 150,000 & 350,000 \\
\hline & $\mathrm{D}$ & $2,250,000$ & $75 \%$ & 300,000 & 75,000 & 375,000 \\
\hline & $\mathrm{E}$ & $3,000,000$ & $100 \%$ & 400,000 & 0 & 400,000 \\
\hline & $\mathrm{F}$ & & & 0 & 75,000 & 75,000 \\
\hline \multirow{3}{*}{$\begin{array}{c}\text { Grand } \\
\text { Total }\end{array}$} & \multicolumn{3}{|c|}{ Maximum } & $2,200,000$ & $2,200,000$ & $2,963,330$ \\
\hline & \multicolumn{3}{|c|}{ Minimum } & 0 & $\mathbf{0}$ & $1,800,000$ \\
\hline & \multicolumn{3}{|c|}{ Negotiation Breakdown } & $-526,882$ & $-526,882$ & $-1,053,763$ \\
\hline
\end{tabular}

Notes: Issue 1: rapid inflation of steel, Issue 2: additional sky garden, Issue 3: prolonged inclement weather, and Issue 4: change of supplier; amount ${ }^{\mathrm{i}}$ : Figure is a collective representation of the time, cost quality implied in each option which is not necessarily proportion among disputes; $\mathrm{F}^{\mathrm{ii}}$ : negotiation breakdown and its consequence is that (a) the dispute issue is left unresolved; (b) the dispute issue is referred to mediation, arbitration or litigation; or (c) the contract is determined; Negotiators are allowed beholding their own payoff and are not allowed to exchange preference charts. 
tors' interests were opposite. Upon completion of the experiment, a shopping coupon of HK\$100 (about US\$12) was presented as a token of thanks. There was no other incentive in relation to the outcome of the negotiation (Patton, Balakrishnan 2010). For analysis purposes, negotiation outcomes are classified according to the monetary returns as represented by the negotiated settlement options (Olekalns, Smith 2003). To achieve high individual and joint gains, negotiators have to make trade-offs among the four issues (Prietula, Weingart 2011). If negotiators can materialize all the valuable trade-offs, the joint monetary payoffs are $\mathrm{HK} \$ 2,963,330$. Lowest joint gain occurs when negotiators jointly reach $\mathrm{HK} \$ 1,800,000$. Individual maximum and minimum monetary payoffs are HK\$2,200,000 and HK\$0 respectively for both the Contractor and the Developer. If complete breakdown occurs, a debt of HK $\$ 526,882$ shall be incurred by both companies. As an example, if the negotiation ends with the decisions $\mathrm{D}$ for Issue $1, \mathrm{~F}$ for Issue 2, B for Issue 3 and $\mathrm{C}$ for Issue 4, then the Contractor and the Developer get the payoffs $\mathrm{HK} \$ 1,336,102$ and $\mathrm{HK} \$ 1,211,102$ respectively.

\section{Results and discussions}

\subsection{Preliminary analyses}

The experiments were held at a university in Hong Kong with one hundred practicing construction professionals $(n=100)$. Their mean working experience in negotiation was 14.9 years $(S D=9.42$ years). Eighty-four of them were male and sixteen were female. The time taken to complete the experiment varied from 20 to 78 minutes $(S D=14$ minutes). Most of the participants (94\%) accepted the token of thanks at the debriefing session. $36 \%$ and $64 \%$ of the participants were categorized as competitors and cooperators respectively by the decomposed game at the pre-negotiation stage. Participants were assigned with roles and in dyads to achieve a mixture of same- and mixed-gender dyads. All dyads negotiations were run in separate sessions. Fifty participants received "maximize own gain" instructions and the other fifty participants received "maximize joint gain" instructions. Cooperators were likely to identify their primary objective as "maximize joint gain" notwithstanding the "maximize own gain" instruction by their organizations (44\%). This prompts an interesting issue for future research. There were 32 breakdowns in the 200 issues negotiated (i.e. 16\%). The findings echo other negotiation studies that negotiation breakdown does occur even mutually beneficial offers are possible. The Cronbach's alphas of the measurements for personality and withdrawal used range from 0.82 to 0.91 suggesting that the scales are reliability. The level of unitizing reliability of the coded transcript was high and all kappas are greater than .80 for all categories. In the study, there are 21 categories and the coders agreed on $94 \%$ of the codes assigned.

\section{Hypothesis one}

Table 3 shows the descriptive data of the target variables. The mean of pre-negotiation withdrawal of competitor is significantly higher than that of cooperator $\left(\mu_{\text {competitor }}=\right.$ 4.86; $\mu_{\text {cooperator }}=4.36 ;$-value $\left.=5.23, p=.005\right)$. Thus, hypothesis one $\left(\mathrm{H}_{1}\right)$ is supported. The result suggests that competitor has higher propensity to withdraw. Competitors 
Table 3. Descriptive, reliability and correlation statistic of overall sample $(n=100)$

\begin{tabular}{ccccccccccccc}
\hline \multicolumn{2}{c}{ Variable } & $\mu$ & $\mathrm{SD}$ & 2 & 3 & 4 & 5 & 6 & 7 & 8 & 9 & 10 \\
\hline 1 & Gen. & 0.84 & 0.37 & $.227^{*}$ & .019 & .100 & .094 & .109 & -.109 & -.109 & $-.205^{*}$ & -.114 \\
2 & Exp. & 14.90 & 9.42 & & .181 & $.246^{*}$ & $.337^{* *}$ & $.357^{* *}$ & $-.381^{* *}$ & $-.401^{* *}$ & -.153 & $-.240^{*}$ \\
3 & $\mathrm{WA}_{\text {pre }}$ & 4.76 & 0.88 & & $.822^{* *}$ & $.286^{* *}$ & $.311^{* *}$ & $.249^{*}$ & $-.310^{* *}$ & $-.285^{* *}$ & -.108 & -.132 \\
4 & $\mathrm{WA}_{\text {post }}$ & 2.93 & 1.23 & & $-14.165^{* *}$ & $.910^{* *}$ & $.249^{*}$ & $.243^{*}$ & $-.246^{*}$ & $-.245^{*}$ & -.004 & .086 \\
\hline 5 & $\mathrm{DT}$ & 29.16 & 21.16 & & & $.893^{* *}$ & $.978^{* *}$ & $-.775^{* *}$ & $-.786^{* *}$ & -.075 & -.113 \\
6 & $\mathrm{DT}_{\text {joint }}$ & 58.32 & 41.37 & & & & & $-.780^{* *}$ & $-.804^{* *}$ & -.083 & -.115 \\
\hline 7 & $\mathrm{IN}$ & 17.47 & 12.42 & & & $-3.680^{* *}$ & & $.866^{* *}$ & $.969^{* *}$ & .130 & .170 \\
8 & $\mathrm{IN}_{\text {joint }}$ & 34.94 & 24.07 & & & & $-3.747^{* *}$ & & & .126 & .175 \\
\hline 9 & $\mathrm{NO}$ & $1,107,181$ & 486,341 & & & & & & & & $.720^{* *}$ \\
10 & $\mathrm{NO}_{\text {joint }}$ & $2,214,361$ & 700,050 & & & & & & & & \\
\hline
\end{tabular}

Notes: Gen.: Gender, 0-female, 1-male; Exp.: Experience in year; pre: pre-negotiation; post: postnegotiation; WA: Withdrawal; DT: Distributive tactic; IN: Integrative tactic; NO: negotiation outcome in turn of monetary payoff (in HK\$); $\mu$ : mean; $S D$ : Standard Deviation; Upper-diagonal: Correlation coefficient $r$; Diagonal: Cronbach's alpha; Lower-diagonal: $t$ value; significant level $p,{ }^{*} p<0.05$; $* * p<0.01$.

become more tough and often resist yielding when making concession is less possible to them due to their high aspiration and self-concern (Pruitt, Kim 2004; Prietula, Weingart 2011).

\section{Hypothesis two}

Pre-negotiation withdrawal was positively correlated with own $(r=.31, p=.002)$ and joint distributive tactic $(r=.25, p=.012)$. Furthermore, pre-negotiation withdrawal leads to less frequent use of own and joint integrative tactics $(r=-.31, p=.002$ and $r=$ $-.29, p=.004$ respectively). The results supported hypothesis two $\left(\mathrm{H}_{2}\right)$. It is suggested that withdrawal governs the underlying motive of a negotiator to engage in a particular course of action, that is, the use of different tactics (Lewicki et al. 2010; Pruitt, Kim 2004). Low withdrawing individuals are likely to develop positive perception and seek to understand the positions of the counterparts.

\section{Hypothesis three}

The result of the correlation analysis of pre-negotiation withdrawal and outcome does not support hypothesis three $\left(\mathrm{H}_{3}\right)$ (i.e. $r=-.11, p=.280$ and $r=-.13, p=.190$ for own and joint outcomes respectively). The results suggested that withdrawal and outcome may be independent to each other or there are other intervening variables (Prietula, Weingart 2011). For example, a withdrawing attitude may be seen as a threat and press for concession by the other party. It is further suggested that the composition of dyad may be an intervening variable.

\section{Hypothesis four}

Data was further analyzed using a $2(\mathrm{PE}$ : ID or CR) $\times 2($ TA: DT or IN) $\times 3$ (dyad composition: 2ID, 1ID1CR or 2CR) ANalysis Of VAriance (ANOVA). Table 4 shows that the patterns of means are in the predicted direction for both competitors and co- 
operators. Competitors use more distributive tactics and less integrative tactic than cooperators. Hypothesis four $\left(\mathrm{H}_{4}\right)$ is thus supported. Moreover, competitors reported less use of distributive and more use of integrative tactics when they were negotiating with cooperators. This finding informs the importance of membership of a negotiation team (Olekalns, Smith 2003). In addition, the result suggests that negotiators representing Developer were generally more competitive $(F=9.120$, sig. $=.001)$. Competitive representatives of Developer use more distributive tactics than that of Contractor $(F=$ 10.732, sig. $=.000)$. Nevertheless, cooperators achieved better payoff irrespective of which side they represent $(F=13.161$, sig. $=.000)$. A summary of the payoff by personality and role is given in Table 5. This finding highlights the role of negotiator impact on her negotiating behavior (Cheung et al. 2009).

\section{Hypothesis five}

The distributive and integrative tactics used by the dyads were tallied. The results show that negotiations conducted in a distributive fashion did not achieve lower joint gain $(r=-.12$, sig. $=.250)$ and an integrative negotiation marginally results in high joint gain

Table 4. Mean comparisons as a function of dyad composition, personality and tactic

\begin{tabular}{ccccccc}
\hline Composition & \multicolumn{2}{c}{ 2ID } & \multicolumn{2}{c}{ 1ID1CR } & \multicolumn{2}{c}{$2 \mathrm{CR}$} \\
\hline TA & DT & IN & DT & IN & DT & IN \\
PE & & & & & & - \\
\hline ID & $33.79^{\mathrm{e}}$ & $15.36^{\mathrm{a}}$ & $29.55^{\mathrm{d}}$ & $17.18^{\mathrm{b}}$ & - & - \\
\hline CR & - & - & $28.23^{\mathrm{cd}}$ & $18.41^{\mathrm{b}}$ & $27.90^{\mathrm{c}}$ & $17.83^{\mathrm{b}}$ \\
\hline
\end{tabular}

Note: Means that do not share a common letter in the subscript differ at $p<.05$ in Tukey's Honestly Significant Difference tests; PE: Personality; ID: Competitor; CR: Cooperator; 2ID: Two Competitors in the dyad; 2CR: Cooperator in the dyad; 1ID1CR: One Competitor and One Cooperator in the dyad; TA: Tactic; DT: Distributive tactic; IN: Integrative tactic.

Table 5. Mean comparison of monetary and performance payoff as a function of personality and role

\begin{tabular}{lcccc}
\hline \multirow{2}{*}{ PE } & Role & Statistic & \multicolumn{3}{c}{ Monetary payoff (HK\$) } \\
\cline { 3 - 5 } & & Contractor & Developer & Overall \\
\hline ID & $\mu$ & $1,051,976$ & $1,069,402$ & $1,060,689$ \\
& $S D$ & 482,998 & 619,876 & 547,743 \\
& $n$ & 18 & 18 & 36 \\
CR & $\mu$ & $1,111,486$ & $1,155,178$ & $1,133,332$ \\
& $S D$ & 515,309 & 382,329 & 450,640 \\
& $n$ & 32 & 32 & 64 \\
\hline Overall & $\boldsymbol{\mu}$ & $\mathbf{1 , 0 9 0 , 0 6 2}$ & $\mathbf{1 , 1 2 4 , 2 9 9}$ & $\mathbf{1 , 1 0 7 , 1 8 1}$ \\
& $\boldsymbol{S D}$ & $\mathbf{4 9 9 , 7 6 6}$ & $\mathbf{4 7 6 , 9 8 9}$ & $\mathbf{4 8 6 , 3 4 1}$ \\
& $\boldsymbol{n}$ & $\mathbf{5 0}$ & $\mathbf{5 0}$ & $\mathbf{1 0 0}$ \\
\hline
\end{tabular}

Note: PE: Personality; ID: Competitor; CR: Cooperator; $\mu$ : mean; $S D$ : Standard Deviation; $n$ : number of samples. 
$(r=.18$, sig. $=.080)$. Thus, hypothesis five $\left(\mathrm{H}_{5}\right)$ is not supported. It is explained that when negotiating parties truly value one another's outcomes, they would have to face a dilemma of enabling better outcomes for the other but not at their own expense. In this situation, the use of distributive tactics may have the effect of forcing the parties to actively participate in the exploration process and allow parties to locate every possible tradeoff (Olekalns, Smith 2013). In addition, distributive negotiation is likely to induce post-negotiation withdrawal $(r=.24$, sig. $=.015)$ and integrative negotiation does lead to reduction in post-negotiation withdrawal $(r=-.25$, sig. $=.014)$.

\subsection{Summary of hypotheses testing}

The personality-tactic relationship has been explored by examining the relationships among states of withdrawal, personality, tactics and negotiation outcomes. The rationality assumption was experimentally tested, while there were 32 breakdowns out of the 200 issues negotiated even mutually profitable options for a settlement are available. The findings further suggested that $\left(\mathrm{H}_{1}\right)$ competitors are more likely to withdraw than cooperators; $\left(\mathrm{H}_{2}\right)$ increasing withdrawal leads to more frequent use of distributive and less frequent use of integrative tactics and $\left(\mathrm{H}_{4}\right)$ competitors use more distributive tactics. Other interesting findings for future study include: (1) frequent use of distributive tactics consequently led to higher withdrawal and (2) the presence of a cooperator facilitates the development of an integrative environment. These findings support the premise that the prospect of a negotiation is governed by the composition of the negotiation dyads, the state of withdrawal and the tactics used. Material reciprocation in information exchanges paves the path to genuine discussion. Thus, process management is paramount.

\subsection{Limitations}

There are several caveats for this study. First, there is a wide array of behavior to choose between contracting parties. The options may be non-commensurable. Simplifying the options for comparison purposes may cause the loss of generality. For example, coding and pure monetary outcome may oversimplify the complexity of negotiation. Second, having data from 100 subjects for the experiment is relatively low. To make the model more precise and concise, a larger sample size is desirable. Moreover, the participation of experienced construction practitioners as subjects for the study instead of student subjects has added authenticity of the study. Third, preliminary analysis showed that the gender composition of negotiating dyads affects their use of negotiator tactics. Male negotiators use less distributive tactics when they negotiate with a female counterpart $(F=10.972$, sig. $=.000)$. However, it is not further elaborated in the study because of the relatively small number of female subjects $(n=16)$. Lastly, the data set is from Hong Kong and this geographical characteristic need to be considered in interpreting the research findings. It is suggested that Chinese negotiation emphases on face giving, development of benign relationships and harmonious social structure. 


\section{Conclusions}

Negotiation involves striking deals by parties of incompatible interests. Negotiators to certain extent are mutually interdependent, in particular where outcomes that are jointly valued and targeted. Tactics are used by negotiators to achieve their desired outcomes that may just be own outcome maximization or optimal mutual gain. Personality plays a pivotal part on the choice of tactics. Moreover, mixed predictions of the personalitytactic relationship have been derived from prior studies, thus suggesting the possibility of other intervening factors. This study examined the role of withdrawal, as an intervening variable, in the negotiator personality-tactic relationship. State of withdrawal refers to the level of interest to continue with a negotiation. In a state of complete withdrawal, the interest to continue no longer exists and breakdown of the negotiation is inevitable. Five hypotheses have been developed in this regard to examine the relationship among personality, tactic and withdrawal. A negotiation experiment including four dispute issues was used to collect data to test the hypotheses. Experienced construction professionals were the subjects. The results suggest that (1) competitors generally have higher level of withdrawal; (2) competitors are more likely to use distributive tactics than cooperators; (3) the higher the level of withdrawal, the more likely the negotiation to be conducted in distributive fashion. It is suggested that highly withdrawing negotiators will conduct a negotiation competitively and the chance of failing to identify possible mutually beneficial negotiated settlement is higher. The state of withdrawal and personality of a negotiator influence the way he evaluates the motives and intentions of the counterparts when a particular tactic is exercised. For example, a request for further information can be viewed as a refusal or search for common ground. This study contributes to the body of negotiation studies by factoring the influence of state of withdrawal in the personality-tactic relationship. The theoretical implication of the study is the importance of appropriate measures of dyadic interaction in negotiations research. The findings suggest how the quality of negotiated agreements in construction disputes can be measured in an experimental research on dyadic and mixed-motive negotiations. It is suggested that withdrawal and breakdown have been largely ignored as a dependent variable and that failure to take them into account may distort experimental results. In addition, the result shows that withdrawal can vary across experimental treatments as a result of differentials in the use of tactic. The findings timely remind construction managers about the need to have an appropriate team composition, by personality as well as technical skill and knowledge.

\section{Acknowledgement}

The authors are grateful for the constructive and useful comments of the Editor-in-Chief and the reviewers which helped to improve the paper.

\section{Funding}

The work described in this paper was fully supported by a Grant from the Research Grant Council of the Hong Kong Special Administrative Region, China (Project no. 111707). 


\section{References}

Bakeman, R.; Robinson, B. F. 2005. Understanding statistics in the behavioral sciences. Mahwah, NJ: Lawrence Erlbaum Associates.

Bhanugopan, R.; Fish, A. 2006. An empirical investigation of job burnout among expatriates, Personnel Review 35(4): 449-468. http://dx.doi.org/10.1108/00483480610670607

Brett, J. M.; Olekalns, M.; Fiedman, R.; Goates, N.; Anderson, C.; Lisco, G. C. 2007. Sticks and stones: language, face, and online dispute resolution, Academy of Management Journal 50(1): 85-99. http://dx.doi.org/10.5465/AMJ.2007.24161853

Cheung, S. O.; Chow, P. T. 2011. Withdrawal in construction project dispute negotiation, Journal of Construction Engineering and Management 137(12): 1071-1079.

http://dx.doi.org/10.1061/(ASCE)CO.1943-7862.0000388

Cheung, S. O.; Yiu, T. W. 2006. Are construction disputes inevitable?, IEEE Transactions on Engineering Management 53(3): 456-470. http://dx.doi.org/10.1109/TEM.2006.877445

Cheung, S. O.; Chow, P. T.; Yiu, T. W. 2009. Contingent use of negotiators' tactics in construction dispute negotiation, Journal of Construction Engineering and Management 135(6): 466-476. http://dx.doi.org/10.1061/(ASCE)0733-9364(2009)135:6(466)

Cropanzano, R.; Rupp, D. E.; Byrne, Z. S. 2003. The relationship of emotional exhaustion to work attitudes, job performance, and organizational citizenship behaviors, Journal of Applied Psychology 88(1): 160-169. http://dx.doi.org/10.1037/0021-9010.88.1.160

Folger, J. P.; Hewes, D.; Poole, M. S. 1984. Coding social interaction, in B. Dervin, M. J. Voigt (Eds.). Progress in communication science. Norwood: Ablex, 115-161.

Kesting, P.; Smolinski, R. 2007. When negotiations become routine: not reinventing the wheel while thinking outside the box, Negotiation Journal 23(4): 419-438.

http://dx.doi.org/10.1111/j.1571-9979.2007.00153.x

Lewicki, R. J.; Barry, B.; Saunders, D. M. 2010. Individual differences, in R. J. Lewicki, B. Barry, D. M. Saunders (Eds.). Negotiation. $6^{\text {th }}$ Ed. Boston, MA: McGraw Hill, 363-393.

O'Connor, K. M.; Gladstone, E. 2015. How social exclusion distorts social network perceptions. Social Networks 40: 123-128. http://dx.doi.org/10.1016/j.socnet.2014.09.002

Olekalns, M.; Smith, P. L. 2013. Dyadic power profiles: power-contingent strategies for value creation in negotiation, Human Communication Research 30: 3-20.

http://dx.doi.org/10.1111/j.1468-2958.2012.01440.x

Olekalns, M.; Smith, P. L. 2003. Testing the relationships among negotiators' motivational orientations, strategy choices, and outcomes, Journal of Experimental Social Psychology 39(2): 101-117. http://dx.doi.org/10.1016/S0022-1031(02)00520-6

Patton, C.; Balakrishnan, P. V. 2010. The impact of expectation of future negotiator interaction on bargaining processes and outcomes, Journal of Business Research 63(8): 809-816.

http://dx.doi.org/10.1016/j.jbusres.2009.07.002

Prietula, M.; Weingart, L. R. 2011. Negotiation offers and the search for agreement, Negotiation and Conflict Management Research 4: 77-109.

http://dx.doi.org/10.1111/j.1750-4716.2011.00074.x

Pruitt, D. G.; Kim, S. H. 2004. Social conflict: escalation, stalemate and settlement. $3^{\text {rd }}$ ed. New York: McGraw Hill.

Rhoades, J. A.; Arnold, J.; Jay, C. 2001. The role of affective traits and affective states in disputants' motivation and behavior during episodes of organizational conflict, Journal of Organizational Behavior 22(3): 329-345. http://dx.doi.org/10.1002/job.72

Rodriguez Mosquera, P. M.; Fischer, A. H.; Manstead, A. S. R.; Zaalberg, R. 2008. Attack, disapproval, or withdrawal? The role of honour in anger and shame responses to being insulted, Cognition and Emotion 22(8): 1471-1498. http://dx.doi.org/10.1080/02699930701822272 
Sinaceur, M.; Tiedens, L. Z. 2006. Get mad and get more than even: when and why anger expression is effective in negotiations, Journal of Experimental Social Psychology 42(3): 314-322. http://dx.doi.org/10.1016/j.jesp.2005.05.002

Thompson, L. L. 2012. The mind and heart of the negotiator. $5^{\text {th }}$ ed. Boston: Pearson.

Toma, C.; Corneille, O.; Yzerbyt, V. 2012. Holding a mirror up to the self egocentric similarity beliefs underlie social projection in cooperation, Personality and Social Psychology Bulletin 38(10): 1259-1271. http://dx.doi.org/10.1177/0146167212449022

Volkema, R. J.; Fleck, D.; Hofmeister, A. 2010. Predicting competitive-unethical negotiating behavior and its consequences, Negotiation Journal 26(3): 263-286.

http://dx.doi.org/10.1111/j.1571-9979.2010.00273.x

Yiu, T. W.; Cheung, S. O.; Chow, P. T. 2008. Logistic regression modeling of construction negotiation outcomes, IEEE Transactions on Engineering Management 55(3): 468-471.

http://dx.doi.org/10.1109/TEM.2008.922630

Pui Ting CHOW is a postdoctoral fellow in the Department of Architecture and Civil Engineering City University of Hong Kong, Kowloon, Hong Kong, China. Her current research interests include mathematical modeling of construction dispute negotiation and construction conflict.

Sai On CHEUNG is a professor in Construction Dispute Resolution Research Unit, Department of Architecture and Civil Engineering, City University of Hong Kong, Kowloon, Hong Kong, China. He has extensive practical experience in handling contractual matters and claims. His research interests include organization issues in construction, contract and dispute management.

Chiu Yan YOUNG received the B.Sc. (Hons.) degree in surveying from the City University of Hong Kong, Kowloon, Hong Kong, China, in 2009. She is a practicing chartered quantity surveyor in a leading cost consultant.

Chi Kit WAH received the B.Sc. (Hons.) degree in surveying from the City University of Hong Kong, Kowloon, Hong Kong, China, in 2010. He is a practicing quantity surveyor in a leading cost consultant. 